
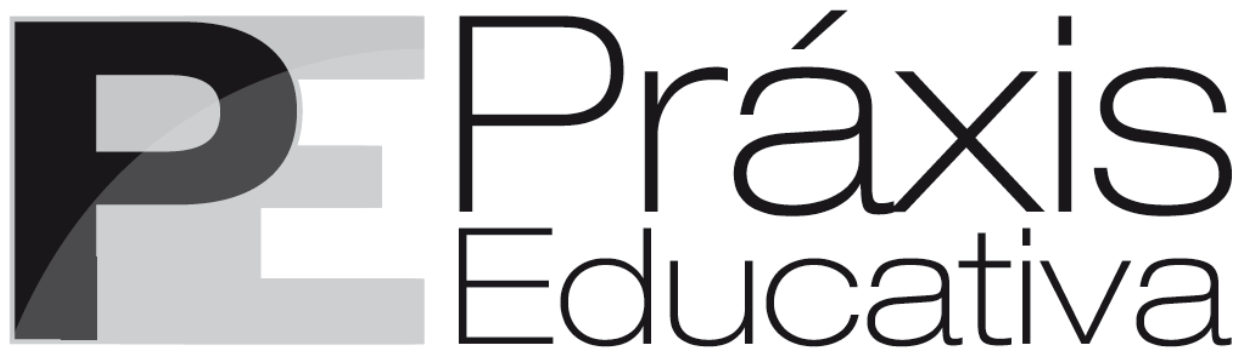

ISSN 1809-4031

elSSN 1809-4309

https://doi.org/10.5212/PraxEduc.v.15.14901.030

\title{
A pesquisa em Política Educacional: análise de aspectos teórico- epistemológicos em teses de Doutorado (2010-2012)
}

\section{Research in Education Policy: analysis of the theoretical-epistemological aspects in Doctoral dissertations (2010-2012)}

\section{La investigación en Política Educativa: análisis de aspectos teórico- epistemológicos en tesis de Doctorado (2010-2012)}

Carina Tonieto*

https://orcid.org/0000-0001-9066-9637

Altair Alberto Fávero **

http://orcid.org/0000-0002-9187-7283

\begin{abstract}
Resumo: As fragilidades epistemológicas (teórico-metodológicas) das pesquisas e a pouca produção de estudos que discutam tais questões no campo da Política Educacional são apontadas pela literatura como um desafio para a consolidação do campo e para a formação de pesquisadores. Tais apontamentos têm levado a questionamentos a respeito da cientificidade de tais estudos, o que tem colocado aos pesquisadores a necessidade de avaliação das pesquisas e seu contexto de produção, assim como a compreensão de suas características, fragilidades e potencialidades para o aprimoramento do campo e das temáticas de estudo ligados à Política Educacional. Na intenção de contribuir com esse debate, este artigo tem por escopo apresentar o resultado da análise de 27 teses produzidas nos Programas de Pós-Graduação em Educação brasileiros com Doutorado, nas linhas de pesquisa de Política Educacional, no período de 2010-2012, a fim de verificar a presença ou não das fragilidades epistemológicas apontadas pela literatura.
\end{abstract}

Palavras-chave: Fragilidade epistemológica. Análise de teses. Política Educacional.

Abstract: The epistemological (theoretical-methodological) weaknesses of research and the little production of studies that discuss such issues in the field of education policy are pointed out by the literature as a challenge for the consolidation of the field and researchers' education. Such notes have led to questions about the scientificity of such studies, which has placed to researchers the need of evaluating the research and its context of production, as well as the understanding of its characteristics, weaknesses and potentialities in order to improve the field and the study themes linked to education policy. With the

\footnotetext{
* Professora do Instituto Federal de Educação Ciência e Tecnologia do Rio Grande do Sul - Campus Ibirubá - Brasil. Doutora em Educação pela Universidade de Passo Fundo - Brasil. E-mail: <tonieto.carina@gmail.com>.

** Professor da Universidade de Passo Fundo - Brasil. Doutor em Educação pela Universidade Federal do Rio Grande do Sul - Brasil. E-mail: <altairfavero@gmail.com>.
} 
intention of contributing to this debate, this paper aims to present the result of the analysis of 27 doctoral dissertations produced in Brazilian Graduate Programs in Education with a Doctorate, in the research lines of education policy, in the period 2010-2012, so as to verify the presence or not of the epistemological weaknesses pointed out by the literature.

Keywords: Epistemological fragility. Analysis of doctoral dissertations. Education policy.

Resumen: Las fragilidades epistemológicas (teórico-metodológicas) de las investigaciones y la escasa producción de estudios que discutan tales cuestiones en el campo de la política educativa, son señalados por la literatura como un desafío para la consolidación del campo y para la formación de investigadores. Tales señalamientos han llevado a cuestionamientos respecto a la veracidad científica de tales estudios, lo que ha colocado a los investigadores en la necesidad de evaluación las investigaciones y su contexto de producción, así como la comprensión de sus características, fragilidades y potencialidades para la mejora del campo y de las temáticas de estudio relacionadas con la política educativa. Con la intención de contribuir a este debate, este artículo tiene como alcance presentar el resultado del análisis de 27 tesis producidas en los Programas de Posgrado en Educación brasileños con Doctorado en las líneas de investigación de política educativa, en el periodo de 2010-2012, a fin de verificar la presencia o no de las fragilidades epistemológicas señaladas por la literatura.

Palabras clave: Fragilidad epistemológica. Análisis de tesis. Política educativa.

\section{Introdução}

O cenário da pesquisa em Educação, mais especificamente em Política Educacional protagonizado pelos programas de Pós-Graduação em Educação, é amplamente analisado na literatura. Esses estudos produzem análises a respeito do cenário mais amplo da Pós-Graduação em Educação (MACEDO; SOUZA, 2010), dos aspectos teórico-metodológicos das pesquisas em educação (GATTI, 2012) e da pesquisa em Política Educacional (DIOGÉNES, 2014; ESPINOZA, 2009; MARTINS, 2011), bem como analisam as disputas de poder e a construção das elites acadêmicas no campo da Política Educacional (GUIMARÃES, 2019), a produção acadêmica no contexto dos programas (BELLO; JACOMINI; MINHOTO, 2014, 2016; MOREIRA, 2019), a divulgação das pesquisas no principal evento da área da Educação, a reunião anual da Associação Nacional de Pós-Graduação e Pesquisa em Educação -ANPEd (SOUZA, 2014). Tais estudos buscam apontar, por um lado, as características e as tendências das pesquisas acadêmicas, elaborar indicativos para a qualificação delas e para a superação de dificuldades inerentes ao processo de expansão e de qualificação da Pós-Graduação brasileira; e, por outro, como tais problemas teórico-metodológicos têm afetado a produção acadêmica em política educacional.

A fragilidade epistemológica das pesquisas em Política Educacional ligadas à falta de teorização, é uma crítica recorrente na análise de políticas, o que, para Frey (2000, p. 215), é explicável em razão de que o interesse da policy analysis é a "empiria e a prática política", o que tem levado muitos estudiosos a "contestar a cientificidade da policy analysis pela falta de teorização". No contexto brasileiro, aspectos relacionados às características e tendências teórico-epistemológicas das pesquisas do campo da Política Educacional têm sido exploradas em diversos estudos, como os de Mainardes (2009, 2016, 2017, 2018a, 2018b), nos quais se aponta a falta e/ou frágil explicitação dos referenciais teóricos que fundamentam as análises, a predominância do emprego da teorização combinada como referencial teórico (teorias, conceitos e contribuições de autores de diferentes), valorização dos processos locais, pouca articulação com o cenário social, político e 
econômico mais amplo, frágeis relações entre a política estudada e as demais políticas implementadas no mesmo período e a falta de relação entre as políticas e o contexto histórico ${ }^{1}$.

A problemática da fragilidade teórica das pesquisas em Educação (de modo geral) e em Política Educacional (de modo mais específico) foi analisada por Fávero e Tonieto (2016) no qual evidenciou-se o "recuo da teoria", não somente no campo educacional e das políticas educativas, mas também no campo das práticas sociais, econômicas e políticas, o qual tem contribuído para a consolidação das "epistemologias da prática" na formação de professores e nas pesquisas em educação (MORAES, 2003, 2009; BHASKAR, 1993).

As fragilidades epistemológicas (teórico-metodológicas) das pesquisas e a pouca produção de pesquisas que discutam tais questões no campo de Política Educacional é apontada pelos estudos que analisaram dissertações e teses (BELLO; JACOMINI; MINHOTO, 2014, 2016; SILVA; JACOMINI, 2014, 2016; MAINARDES, 2009; MOREIRA, 2019; MAINARDES; STREMEL, 2020), de trabalhos apresentados em eventos científicos (SOUZA, 2014) e de artigos publicados em periódicos (TELLO; MAINARDES, 2012; MAINARDES, 2009, 2016, 2017, 2018a). Tais estudos foram motivadoras do estudo aqui apresentado, que consiste na análise das teses produzidas nos Programas de Pós-Graduação em Educação brasileiros com Doutorado, nas linhas de pesquisa de Política Educacional, no triênio 2010-2012, a fim de verificar a presença ou não das fragilidades epistemológicas apontadas pela literatura.

\section{Aspectos epistemológicos (teórico-metodológicos) da pesquisa}

O estudo analisou as teses vinculadas às linhas de pesquisa de política educacional, no triênio 2010-2012, a fim de identificar as questões teórico-metodológicas presentes nos relatórios. A investigação consistiu em um recorte de uma pesquisa mais ampla a respeito da produção acadêmica em Política Educacional (TONIETO, 2018). O problema de pesquisa que se buscou enfrentar consiste na seguinte pergunta: as teses defendidas no triênio 2010-2012 apresentam as fragilidades teórico-metodológicas apontadas pela literatura e quais são suas consequências para o campo acadêmico da Política Educacional? A hipótese inicial era a de que as fragilidades epistemológicas estariam presentes na amostra selecionada e que corroborariam as afirmações da literatura, sinalizando para as dificuldades apontadas para consolidação do campo acadêmico da Política Educacional.

A opção pelas teses está ligada ao fato de que: os cursos de Doutorado são uma referência na produção de pesquisa no Brasil (OLIVEIRA, 2015); todos os programas com teses defendidas no período 2010-2012, independentemente do seu conceito, visto que contribuem para a produção acadêmica do campo de Política Educacional; as linhas de pesquisa cuja redação contemplava somente os termos Política/s Educacional/is e/ou Pública/s, por considerar que o campo acadêmico comporta uma multiplicidade de pesquisas em interface com campos correlatos. Além disso, fazendo tal delimitação, seria possível identificar os interesses mais perenes dos investigadores do campo; e, por fim, a escolha do período (triênio 2010-2012) por se tratar de uma produção acadêmica ainda não analisada para tais fins.

\footnotetext{
${ }^{1}$ A análise de características e tendências teórico-epistemológicas das pesquisas do campo da Política Educacional tem sido um dos aspectos enfatizados por pesquisadores da Red de Estudios Teóricos y Epistemológicos en Política Educativa (Relepe - www.relepe.org). Ver, por exemplo, entre outros, Mainardes (2018a, 2018b); Mainardes e Tello (2016); Moreira (2019); Stremel e Mainardes (2020); Silva e Jacomini (2016); Tello e Mainardes (2015b) e Tonieto (2018).
}

Práxis Educativa, Ponta Grossa, v. 15, e2014901, p. 1-21, 2020 Disponível em: <https://www.revistas2.uepg.br/index.php/praxiseducativa> 
A pesquisa em Política Educacional: análise de aspectos teórico-epistemológicos...

O método utilizado foi o dedutivo-analítico, já que se partiu da premissa geral de que toda a pesquisa científica obedece a critérios epistemológicos (teórico-metodológicos), para identificar sua presença ou não em uma amostra específica (teses). $O$ referencial teórico racionalista, considerado na sua vertente histórica (BACHELARD, 1968, 1977, 1979, 1990, 1996) e crítica (POPPER, 1975, 2004, 2008, 2013), ancorou a formulação do problema, escolhas metodológicas, análise dos resultados e conclusões. As premissas teóricas que ancoraram o estudo foram: epistemologia como processo e produto histórico que busca compreender o modo como se produz conhecimento; produção do conhecimento é um processo orientado teoricamente que busca a resolução de problemas que não são dados, mas criados e elaborados teoricamente pelos sujeitos em interação com a realidade; a produção do conhecimento é movida por interesses (obstáculos epistemológicos e ideológicos), e, portanto, fazem-se necessárias a vigilância epistemológica e o processo de crítica intersubjetiva de modo a garantir a objetividade científica; toda pesquisa científica é composta de escolhas teóricas e metodológicas, porém são as escolhas teóricas que orientam as escolhas metodológicas; toda pesquisa é uma tentativa de resposta para um problema; antes de tudo elabora-se teoricamente um problema e sua possível solução, para, depois, testá-lo submetendo-o à crítica intersubjetiva; as tentativas de resposta devem ter validade lógica e, por isso, devem ser submetidas à avaliação constante; conhecimento científico é sempre provisório, estando sempre sujeito a revisões, de onde provém seus caráter falibilista.

A pesquisa caracteriza-se: quanto à sua natureza como básica, pois busca contribuir para a discussão da produção do conhecimento no campo da Política Educacional; quanto à abordagem do problema é qualitativa, recorrendo ao recurso quantitativo de porcentagem simples (ESTEBAN, 2010); quanto aos seus objetivos, é descritiva-analítica, já que se busca descrever e analisar as características das teses; quanto aos seus procedimentos, é uma metapesquisa compreendida como "[...] uma estratégia para a análise sistemática das pesquisas de um determinado campo ou temática" (MAINARDES, 2018b, p. 304), diferentemente da revisão de literatura por focalizar a "[...] avaliação das pesquisas, identificar características, tendências, fragilidades e obstáculos para o desenvolvimento de um campo ou temática de pesquisa" (MAINARDES, 2018b, p. 306). Desse modo, conforme Tello e Mainardes (2015a, p. 166) e Mainardes (2018b), a metapesquisa intenta analisar o processo de pesquisa presente em um determinado conjunto de produções acadêmicas, com enfoque nos fundamentos teóricos das pesquisas e a implicação para o campo de estudo à que estão vinculadas tais pesquisas. $\mathrm{O}$ procedimento adotado para a composição da amostra foi a análise dos Cadernos de Indicadores da Coordenação de Aperfeiçoamento de Pessoal de Nível Superior - Capes (2010, 2011, 2012), nos quais os Programas informam periodicamente as teses e as dissertações defendidas por linha de pesquisa.

O enfoque empregado é o das Epistemologias da Política Educacional (EEPE), o qual consiste em uma proposta de análise da produção do conhecimento em Política Educacional potente para identificar duas fragilidades epistemológicas do campo: a falta de explicitação do posicionamento epistemológico do investigador, por partirem da concepção de neutralidade e de objetividade no processo de investigação, impossibilitando a reflexividade epistemológica ${ }^{2}$ sobre seu próprio processo de investigação; e muitas investigações seguem metodologias de autores referenciais sem desenvolver sua base epistemológica, misturando técnicas, autores e perspectivas epistemológicas que geram inconsistência epistemológica no processo de investigação, tendendo ao ecletismo epistemológico (TELLO, 2012, 2013; TELLO; MAINARDES, 2015a).

\footnotetext{
2 Tello (2012, p. 55) usa tal conceito amparado na leitura que faz de Bourdieu, esclarecendo que a compreende como ligada à vigilância epistemológica para desenvolver uma investigação sólida e coerente, à dimensão ética e ao compromisso social do investigador com a realidade.
}

Práxis Educativa, Ponta Grossa, v. 15, e2014901, p. 1-21, 2020 Disponível em: <https://www.revistas2.uepg.br/index.php/praxiseducativa> 
O EEPE é composto por três elementos: perspectiva epistemológica, posicionamento epistemológico e enfoque epistemetodológico (TELLO; MAINARDES, 2015a). A perspectiva epistemológica "[...] consiste na cosmovisão que o pesquisador assume para guiar a sua pesquisa" (TELLO; MAINARDES, 2015a, p. 157), isto é, na concepção de mundo que orienta o olhar do pesquisador ou o seu modo de ver a realidade. Conforme Bachelard (1996), o espírito que produz cultura científica nunca é jovem, ele tem a idade de seus preconceitos, e é impossível eliminar todos os conhecimentos habituais que muitas vezes impedem que se veja o que deveria saber; dessa forma, são "obstáculos epistemológicos" que podem ser contornados pela vigilância epistemológica de si. Na visão de Popper (1975), os sujeitos compreendem o mundo a partir de um "horizonte de expectativas", que funciona como uma moldura de referência a partir da qual conferem significado para as suas experiências, sendo essas as concepções de mundo do sujeito. Essas concepções orientam o olhar do pesquisador (ele não é neutro), quer ele queira ou não, e, desse modo, podem conduzir tanto a tentativa forçada de adequar a teoria à realidade ou à realidade à teoria, de onde produzirá compreensões que serão socializadas; por isso, implica um posicionamento ético-político do investigador.

O posicionamento epistemológico consiste nas opções teóricas ligadas ao campo de estudo que estão em relação direta com o conteúdo teórico/empírico da pesquisa. Para os autores, esse é o ponto central da EEPE, pois é onde se "põe em jogo a presença da cosmovisão do investigador", isto é, o modo de o investigador ler a realidade e construí-la em termos de reflexividade epistemológica (TELLO; MAINARDES, 2015a, p. 157). É nesse movimento que o "posicionamento epistemológico" se converte em "posicionamento ético-político", ligado ao "posicionamento ontológico". Pode-se afirmar que tais constatações a respeito do posicionamento epistemológico estão de acordo com a posição de Bachelard (1977) e de Popper (1975). O primeiro afirma que toda produção do conhecimento é informada teoricamente e nunca de um modo neutro, o que implica reconhecer que o pesquisador não encontra problemas ou dados, mas os constrói a partir de determinados referenciais teóricos. O segundo destaca que a ciência trabalha com problemas que são teóricos e a produção do conhecimento é resultado de uma tentativa teórica de resolver problemas que o próprio cientista, como sujeito epistemológico, coloca e precisa apontar soluções, as quais são sempre provisórias. Nesse sentido, para Popper (1975), a colocação de problemas de pesquisa é sempre informada teoricamente, a partir do "horizonte de expectativas" a partir da qual se confere significado às experiências, às ações e às observações. Assim, é a teoria que permite colocar problemas, que aponta para onde deve ser focado o interesse, o que e como observar e dá parâmetros para análise dos resultados.

O enfoque epistemetodológico é o "[...] modo como se constrói metodologicamente a pesquisa a partir de uma determinada perspectiva epistemológica e de um posicionamento epistemológico" (TELLO; MAINARDES, 2015a, p. 158). Por isso, na organização metodológica da pesquisa, não existe neutralidade, já que a metodologia é sempre orientada, de onde há a necessidade da "vigilância epistemológica". Nesse caso, não se trata simplesmente da indicação das técnicas e dos instrumentos utilizados na pesquisa, mas da coerência delas com o referencial teórico adotado. Por isso, a coleta de dados e a sua apresentação é apenas um momento da pesquisa, sendo o mais importante o que se tem a dizer sobre os resultados e com que finalidade se diz. Na visão de Bachelard (1977), o "vetor epistemológico" vai do racional para o real, já que a ciência não trata de apenas descrever o real, mas cria os seus objetos, sendo o dado científico resultado de uma construção/elaboração teórica e metódica. O uso da técnica e a geração dos resultados (a experiência científica), nessa perspectiva, são sempre informados pela teoria. Nessa mesma direção está a concepção de Popper (1975), ao afirmar que não "temos" uma observação, mas "fazemos" uma observação, assim, toda técnica é sempre precedida ou orientada por um interesse, por uma indagação ou por um problema, o que a define como algo teórico, portanto, anterior ao processo de experimentação.

Práxis Educativa, Ponta Grossa, v. 15, e2014901, p. 1-21, 2020 Disponível em: < https://www.revistas2.uepg.br/index.php/praxiseducativa> 
A pesquisa em Política Educacional: análise de aspectos teórico-epistemológicos...

A coleta de dados foi realizada por meio da análise textual do conteúdo, a fim de buscar identificar, compreender e interpretar tanto o conteúdo explícito/declarado quanto o implícito/latente (BARDIN, 2011; TELLO; MAINARDES, 2015a). As categorias para organização e análise das informações foram: gênese da pesquisa (ligada à trajetória de vida e/ou à relevância do tema); contribuições da pesquisa; tema; problema; referencial teórico; método; hipótese; caracterização da pesquisa quanto à sua natureza, abordagem do problema, objetivos e procedimentos; lócus da pesquisa; sujeitos da pesquisa; coleta, tratamento e análise dos dados.

$\mathrm{Na}$ medida em que os dados eram identificados, durante a leitura das teses, eram organizados em planilhas de modo a compor o panorama geral da amostra. Concluída a leitura e o preenchimento da planilha, procedeu-se à análise dos dados por categoria, recorrendo ao uso de porcentagem simples para a identificação dos índices de representatividade para apresentação dos resultados. Os resultados foram analisados a partir do referencial teórico racionalista históricocrítico (BACHELARD, 1968, 1977, 1979, 1990, 1996; POPPER, 1975, 2004, 2008, 2013).

\section{Resultados e discussões}

Foram identificadas seis linhas de pesquisa cuja nomenclatura utilizava exclusivamente os termos Política/s Educacional/is e/ou Pública/s nas suas diferentes redações, vinculadas a seis Programas de Pós-Graduação em Educação, conforme Tabela 1.

Tabela 1 - Relação dos Programas de Pós-Graduação em Educação com teses defendidas nas Linhas de Pesquisa de Política Educacional e sua distribuição no triênio 2010-2012

\begin{tabular}{|c|c|c|c|c|}
\hline \multirow[t]{2}{*}{$\begin{array}{l}\text { Instituição/ } \\
\text { Programas }\end{array}$} & \multirow[t]{2}{*}{ Linha de pesquisa } & \multicolumn{3}{|c|}{$\begin{array}{l}\mathrm{N}^{\circ} \text { de teses } \\
\text { defendidas }\end{array}$} \\
\hline & & 2012 & 2011 & 2010 \\
\hline UFMG & $\begin{array}{l}\text { Políticas Públicas e Educação: formulação, implantação e } \\
\text { avaliação }\end{array}$ & 2 & 2 & 6 \\
\hline UFPA & Políticas Públicas Educacionais & 3 & 0 & 0 \\
\hline $\mathrm{UFPB} / \mathrm{JP}$ & Políticas Educacionais & 7 & 1 & 5 \\
\hline UFPR & Políticas Educacionais & 3 & 0 & 0 \\
\hline FUPF & Políticas Educacionais & 0 & 0 & 0 \\
\hline UNINOVE & Políticas em Educação & 1 & 0 & 0 \\
\hline \multirow{2}{*}{\multicolumn{2}{|c|}{$\begin{array}{r}\text { Total por ano } \\
\text { Total de teses defendidas no triênio }\end{array}$}} & 16 & 3 & 11 \\
\hline & & \multicolumn{3}{|c|}{30} \\
\hline
\end{tabular}

Fonte: Elaborada pelos autores a partir dos Cadernos de Indicadores Capes (2010, 2011, 2012).

Do total de teses encontradas, foi possível localizar o texto na íntegra de apenas 28 delas nos repositórios institucionais, já que não estão disponíveis no Banco de Teses da Capes. Das 28 teses, apenas 20 mencionam, nas páginas pré-textuais, a linha de pesquisa a que estavam vinculadas no programa. No cruzamento das informações disponíveis nos Cadernos de Indicadores e nas teses, identificou-se uma tese que pertencia a outra linha de pesquisa e, portanto, foi descartada. Desse modo, 27 teses compuseram o escopo final e foram objeto de análise sistemática por meio da leitura na íntegra.

As descrições das linhas de pesquisa analisadas nos Cadernos de Indicadores da Capes (2010, 2011, 2012) permitiram concluir que elas apresentam com clareza quais são os seus núcleos de interesse, demarcando suas especificidades em relação aos outros campos, porém, internamente, não funcionam apenas como delimitadores de objetos de estudos, mas como orientadores e indutores, a partir dos quais é possível a construção de múltiplos objetos de pesquisa. No entanto, se, de um lado, seria estranho as linhas funcionarem internamente como delimitadores - uma vez 
que uma das propostas da pesquisa científica é colocar e recolocar problemas, os quais surgem e ganham forma a partir das múltiplas experiências de sujeitos inseridos em distintos contextos sociais-culturais-econômicos-políticos e que lançam, para a realidade educacional, uma diversidade de olhares investigativos e orientados teoricamente, a partir dos quais percebem e formulam seus problemas de pesquisas -, por outro, tal abertura, se considerada de forma desmedida, contribui para a diluição das fronteiras do campo, aumentando as chances de todo e qualquer tema estar vinculado ao campo, não trazendo, assim, contribuições para a sua consolidação. Desse modo, funciona mais como agregador de pesquisas do que produtor de conhecimento. Por isso, um dos desafios colocados para a formação dos pesquisadores é a importância e a necessidade de explicitação do seu vínculo com a linha e as contribuições da pesquisa para o campo acadêmico.

Os núcleos temáticos identificados nas seis linhas de pesquisa de Política Educacional estudados apontam para a centralidade de determinados fenômenos considerados relevantes para o campo acadêmico da Política Educacional, os quais são: papel/ações do Estado e da sociedade civil; formação de professores; atuação dos movimentos sociais, sindicatos e partidos políticos; fundamentos e pressupostos das políticas públicas educacionais; avaliação da educação, programas, projetos e propostas educacionais; reformas educacionais: pressupostos, implantação e impacto; gestão da educação; organização de práticas sociais, educativas e escolares; financiamento da educação; papel das agências multilaterais e de formação. Percebe-se que tais eixos tratam de temas centrais para compreender-se e pensar o contexto de formulação, implementação e avaliação de políticas educacionais. No entanto, nenhuma das linhas sinaliza de modo explícito a intencionalidade de investigação a respeito da produção do conhecimento no campo acadêmico da Política Educacional. Talvez por considerar que, como se trata de pesquisas produzidas em ambiente acadêmico, tais discussões estejam implícitas e, portanto, podem articular-se com os eixos temáticos postos.

Um outro desafio, tanto para a formação de pesquisadores quanto para a consolidação do campo, consiste no interesse científico de tematizar, de pesquisar e de discutir a respeito das questões epistemológicas das pesquisas em Política Educacional, uma vez que é a partir desse movimento e dessa intencionalidade que se poderá qualificar as pesquisas e o campo. A fragilidade epistemológica das pesquisas de Política Educacional - principalmente na dimensão teórica, mas com implicações sérias para a metodológica - é preocupante, pois, conforme lembram Bachelard (1968, 1977, 1979, 1990, 1996) e Popper (1975, 2004, 2008, 2013), o olhar do pesquisador é sempre orientado teoricamente para a realidade, o que lhe possibilita colocar problemas que são teóricos e projetar soluções para eles, movimento que também exige esforço teórico apurado a fim de projetar a validação de suas hipóteses por meio de discussões intersubjetivas. Para eles, a objetividade científica consiste, em princípio, na derrubada do mito de que o conhecimento começa com a experiência e que a pura descrição dos fatos é que garante objetividade: a experiência é sempre informada pela teoria, afirmam ambos.

Para Bachelard, o vetor epistemológico na produção do conhecimento segue a direção da razão para experiência, e não o contrário, uma vez que não há uma apropriação direta dos fatos, mas, sim, um processo de construção de um objeto de investigação ou um problema científico que está sempre ancorado teoricamente. Desse modo, os dados científicos são sempre construídos e não achados. Para Popper, acontece algo semelhante. Os objetos científicos são sempre objetos teóricos, já que são fruto de um processo de elaboração e de colocação de problemas possível somente porque são formulados teoricamente. Para ambos, o trabalho teórico é que permite construir explicações cada vez melhores e mais criativas. As fragilidades epistemológicas (teóricometodológicas) das teses, nesse sentido, apontam para a centralidade da teorização para o aprimoramento do campo, das pesquisas e dos objetos de estudo, fazendo frente ao empirismo 
apressado justificado pela necessidade de objetividade científica. No entanto, tal discussão ainda é pouco presente no campo e nas pesquisas.

A análise das teses mostrou que é muito pequena a representatividade das pesquisas voltadas à discussão a respeito da produção do conhecimento no campo acadêmico da Política Educacional no triênio 2010-2012, confirmando o apontamento da literatura para a escassez desses estudos. É esse contexto que corrobora a ausência de tal preocupação, tanto na proposição dos núcleos temáticos das linhas de pesquisa quanto nas teses produzidas no período analisado. Registra-se, nessa perspectiva, a preocupação quanto a tal silenciamento, pois nele pode residir um dos indicadores das fragilidades epistemológicas (teórico-metodológicas) das pesquisas produzidas no campo. Além disso, ressalta-se a importância e a necessidade de pesquisas que analisem a produção acadêmica do campo (TONIETO, 2018; MOREIRA, 2019). Também, foi constatado que a maioria das teses faz referência à linha de Política Educacional; no entanto, poucas (33,33\%) usam a nomenclatura correta, revelando desconhecimento ou mesmo descaso quanto a essa informação. Considerando que todas as teses, necessariamente, estão vinculadas às linhas de pesquisa, soa um tanto estranha a presença da redação incorreta das linhas na grande maioria dos trabalhos, uma vez que tais pesquisas contribuem para a constituição e a consolidação do campo acadêmico como produtor de conhecimento.

Tal sintoma de aparente descaso com o campo acadêmico também pode ser observado na descrição da gênese e das contribuições da pesquisa, conforme Tabela 2. A grande maioria dos pesquisadores apresenta a gênese da pesquisa; entretanto, poucos apresentam as contribuições da pesquisa. Quanto à gênese da pesquisa, é predominante $(81,48 \%)$ a referência às trajetórias de vida (pessoal, profissional e acadêmica) e pequeno o número de pesquisadores $(33,33 \%)$ que associam a tais interesses justificativas vinculadas à relevância do tema para o campo acadêmico. Tais indicativos mostram uma dificuldade e uma fragilidade em relação à capacidade de diálogo com a cultura científica do campo. Nessa mesma direção, estão as contribuições da pesquisa, que foram apontadas por poucos pesquisadores $(29,62 \%)$, dos quais apenas dois $(7,40 \%)$ elencaram, dentre as contribuições, as que têm alcance no campo acadêmico da Política Educacional.

Tabela 2 - Panorama geral da apresentação no texto da tese da gênese, contribuições e tema de pesquisa

(continua)

\begin{tabular}{c|l|c}
\hline \multicolumn{1}{c|}{ Categorias } & \multicolumn{1}{c|}{ Descrição } & $\mathbf{N}^{\mathbf{0}}$ \\
\hline \multirow{4}{*}{ Trajetória de vida } & Trajetória pessoal, profissional e acadêmica. & 20 \\
\cline { 2 - 3 } & Trajetória profissional e acadêmica. & 1 \\
\cline { 2 - 3 } & Trajetória profissional. & 5 \\
\cline { 2 - 3 } & Não fazem referência. & 6 \\
\hline \multirow{5}{*}{ Justificativas } & $\begin{array}{l}\text { Relevância do tema para o campo acadêmico associada à trajetória } \\
\text { pessoal, profissional e acadêmica. }\end{array}$ & 1 \\
\cline { 2 - 3 } & $\begin{array}{l}\text { Relevância do tema para o campo acadêmico associada à trajetória } \\
\text { profissional. }\end{array}$ & 2 \\
\cline { 2 - 3 } & Relevância do tema para o campo acadêmico. & 1 \\
\hline
\end{tabular}

Fonte: Elaborada pelos autores. 
Tabela 2 - Panorama geral da apresentação no texto da tese da gênese, contribuições e tema de pesquisa (conclusão)

\begin{tabular}{|c|c|c|}
\hline Categorias & Descrição & $\mathbf{N}^{\mathbf{o}}$ \\
\hline & Não fazem referência. & 18 \\
\hline \multirow{4}{*}{$\begin{array}{l}\text { Contribuições para o } \\
\text { campo acadêmico }\end{array}$} & $\begin{array}{l}\text { Contribuição "científica e social" e "teórico-metodológica e } \\
\text { empírica" para o campo acadêmico. }\end{array}$ & 2 \\
\hline & $\begin{array}{l}\text { Diferença entre a "academia" e a "Política Educacional brasileira" } \\
\text { produzida pelos governos e sociedade. }\end{array}$ & 1 \\
\hline & $\begin{array}{l}\text { Contribuições direcionadas para uma determinada área: educação } \\
\text { ambiental, educação infantil e direitos humanos. }\end{array}$ & 3 \\
\hline & Não constam contribuições para o campo acadêmico. & 21 \\
\hline
\end{tabular}

Fonte: Elaborada pelos autores.

O objetivo com tais apontamentos não é de acusar ou desqualificar as pesquisas produzidas, mas manifestar a preocupação quanto à dificuldade dos pesquisadores de apontarem as contribuições de suas pesquisas, e, principalmente, para o campo acadêmico, isto é, quais as contribuições da pesquisa - seja ela básica ou aplicada - para o campo que dá sustentação e legitima tais estudos e que tem, dentre os seus desafios, produzir pesquisas que contribuam para o seu desenvolvimento e para a consolidação como espaço de produção de conhecimento. Partindo da premissa de que as pesquisas não são neutras e permeadas por múltiplos interesses, é preocupante o pouco interesse manifestado pelos pesquisadores em relação à constituição e à consolidação do campo acadêmico da Política Educacional e de que os interesses que movem as pesquisas estão muito mais ligados a questões subjetivas do que acadêmicas. Tal tendência, definida por Bachelard e Popper como obstáculos epistemológicos e ideológicos, os quais deveriam ser minimizados pelo exercício da vigilância epistemológica e da crítica, ainda aparece de forma muito expressiva nas teses analisadas, evidenciando uma fragilidade e consistindo em um desafio para a formação de pesquisadores. Isso não significa a supressão dos interesses subjetivos, uma vez que é impossível, mas de sua minimização em favor dos interesses científicos.

Nessa linha de interesses das pesquisas, está posta a escolha dos temas de pesquisa: o que se pesquisou ou foi de interesse dos doutorandos e orientadores no triênio 2010-2012. Nota-se, que nem sempre a temática a ser abordada pela tese é apresentada com clareza; no entanto, é possível inferir, a partir dos objetivos e do problema de pesquisa, conforme consta na Tabela 3.

Tabela 3 - Número de teses por eixo temático

\begin{tabular}{l|c|c}
\multicolumn{1}{c|}{ Eixos temáticos } & $\begin{array}{c}\mathbf{N}^{\mathbf{o}} \text { de } \\
\text { teses }\end{array}$ & $\%$ \\
\hline 1) Organização, planejamento, administração e gestão da educação. & 0 & 0 \\
\hline 2) Avaliação em larga escala e avaliação institucional. & 2 & $7,40 \%$ \\
\hline 3) Qualidade da educação e ensino. & 3 & $11,11 \%$ \\
\hline $\begin{array}{l}\text { 4) Estado e reformas educacionais, neoliberalismo na educação, terceiro setor e } \\
\text { organizações sociais na educação, análise e avaliação de políticas educacionais. }\end{array}$ & 8 & $29,62 \%$ \\
\hline
\end{tabular}

Fonte: Elaborada pelos autores. 
A pesquisa em Política Educacional: análise de aspectos teórico-epistemológicos...

Tabela 3 - Número de teses por eixo temático

\begin{tabular}{|c|c|c|}
\hline & & conclusã \\
\hline 5) Políticas de formação de professor e carreira docente. & 8 & $29,62 \%$ \\
\hline 6) Financiamento da educação e controle social do financiamento da educação. & 0 & 0 \\
\hline 7) Abordagens teórico-metodológicas em pesquisas sobre políticas educacionais. & 1 & $3,70 \%$ \\
\hline 8) Análise e avaliação de programas e projetos no campo educacional. & 5 & $18,51 \%$ \\
\hline 9) Políticas inclusivas. & 0 & 0 \\
\hline Total de teses & 27 & $100 \%$ \\
\hline
\end{tabular}

Fonte: Elaborada pelos autores.

Nota-se que os eixos temáticos 4 e 5 concentram os maiores números de trabalhos, em um total de 16 , equivalendo a aproximadamente $59,25 \%$ das teses defendidas, seguido do eixo $8 \mathrm{com}$ cinco trabalhos. A pesquisa de Bello, Jacomini e Minhoto $(2014,2016)$, ao analisar o resumo da dissertações e das teses no período de 2000-2010, também apontou a centralidade desses três eixos, os quais compunham a relação de eixos com mais de uma centena de trabalhos no geral, conforme consta no Gráfico 1 a seguir. Se tomado como referência somente o número de teses apresentado pelas autoras, confirma-se a tendência de os eixos 4 e 5 comportarem maior número de trabalhos (145 e 73, respectivamente), e o eixo 8 ocupando o quarto lugar, com 33 teses. Desse modo, há uma pequena variação em relação ao lugar ocupado pelo eixo 8 , que, na presente pesquisa, aparece em segundo lugar. No que se refere aos eixos 3 e 2, que, nesta pesquisa, figuram nos terceiro e quarto lugares, respectivamente, na pesquisa de Bello, Jacomini e Minhoto (2014, 2016), considerando apenas os números de teses, esses eixos estão em $6^{\circ}$ (15 teses) e $5^{\circ}$ (31 teses) lugares, respectivamente, apontando para uma inversão. O eixo 3 tem um número superior de teses defendidas, enquanto, na pesquisa de Bello, Jacomini e Minhoto (2014, 2016), o número encontrado é inferior. $\mathrm{O}$ inverso acontece com o eixo 2, que apresenta um número inferior, e, na pesquisa de Bello, Jacomini e Minhoto $(2014,2016)$, apresenta um número superior.

Quanto ao eixo 7, ele contou apenas com uma tese defendida, e, na pesquisa de Bello, Jacomini e Minhoto (2014, 2016), também foi o eixo que menos apresentou teses defendidas (12), confirmando a tendência das linhas de pesquisa em Política Educacional apresentar poucas teses que tratam das questões teórico-metodológicas em pesquisas de/sobre políticas educacionais. Os eixos que apresentaram maior discrepância entre as duas pesquisas foram o 1, 6 e 9, que não contaram com teses vinculadas. Já, na pesquisa de Bello, Jacomini e Minhoto (2014, 2016), contaram respectivamente com 71,21 e 31 teses defendidas. 
Gráfico 1 - Comparativo por período do número de teses defendidas por eixo temático

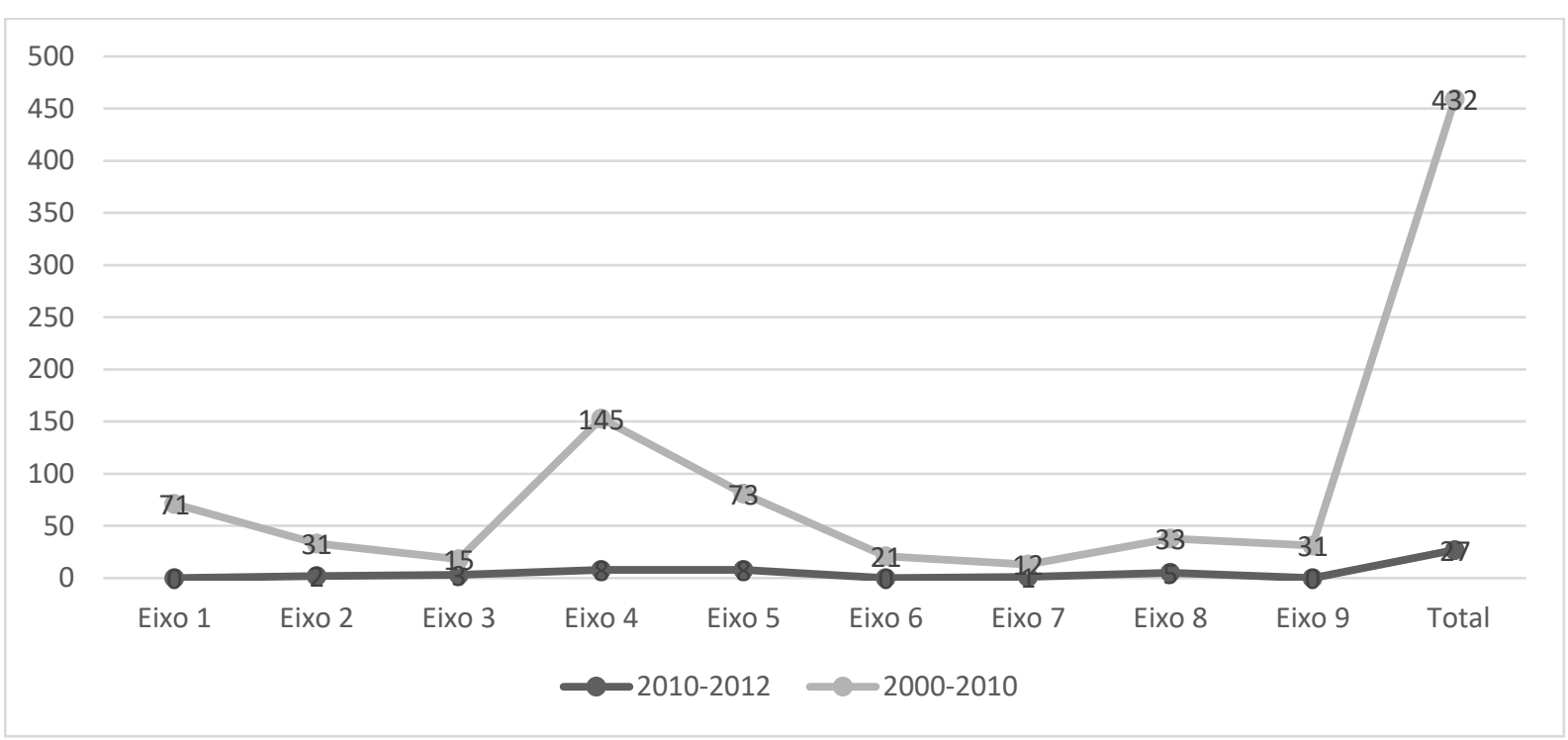

Fonte: Elaborado pelos autores.

Na comparação com o período (2000-2010) analisado por Bello, Jacomini e Minhoto (2016), é possível perceber, por um lado, os interesses mais perenes dos pesquisadores quanto ao eixos que discutem: o papel do Estado, reformas, neoliberalismo, análise e avaliação de políticas e formação e carreira docente (eixos 4 e 5); a avaliação em larga escala e institucional (eixo 2); a qualidade da educação e do ensino (eixo 3); a análise e a avaliação de programas e de projetos (eixo 8); a permanência do pouco interesse na discussão das questões epistemológicas (teóricometodológicas) atinentes à pesquisa em Política Educacional (eixo 7); e, no período analisado, a organização, o planejamento, a gestão, o financiamento e a inclusão não foram de interesse dos pesquisadores vinculados às linhas de Política Educacional (eixos 1, 6 e 9), apresentando a maior descontinuidade, o que não significa que tais temáticas não foram discutidas por linhas correlatas. Apontam, também, para a predominância dos interesses dos pesquisadores em relação a determinados eixos de discussão que são centrais e que marcam a identidade do campo acadêmico como o papel do Estado, a avaliação de políticas, a formação docente, o programa e projetos, e para outros que aparecem de forma mais representativa, dependendo do contexto político e das políticas governamentais, por isso cíclicos. Por outro lado, fica marcada a falta de tradição do campo na investigação a respeito das questões teórico-metodológicas das pesquisas em Política Educacional, sendo colocado como desafio para o próprio campo o investimento em tais pesquisas.

Quanto às características epistemológicas (teórico-metodológicas) das teses defendidas a fim de verificar as continuidades e as descontinuidades em relação à pesquisa desenvolvida por Silva e Jacomini (2016), iniciou-se pela dimensão teórica das teses (referencial teórico, problema de pesquisa e hipótese). O referencial teórico é enunciado pela maioria das teses $(77,77 \%)$, com predominância para a indicação de autores $(51,85 \%)$ em relação às tradições/matrizes teóricas $(25,92 \%)$.

As matrizes/tradições teóricas indicadas nas sete teses são: materialismo histórico e dialético (3), as quais citam como autores referentes Marx e Engels; teoria das representações sociais de Moscovici (1), que já indica o autor referente; autores da primeira geração da Escola de Frankfurt (1), que tem como autores referentes Adorno, Horkeimer e Marcuse; vertente fenomenológica-hermenêutica (1), indicando como autores referentes Bruner, Freire e Nóvoa; 
teoria do pensamento complexo de Morin, pedagogia da autonomia de Paulo Freire e reencantar a educação de Hugo Assmann (1).

Nessas teses, os pesquisadores deixam clara qual a tradição e que autores constituem a ancoragem teórica de toda a tese, em torno dos quais se articulam comentadores e outros teóricos que ajudam na compreensão da problemática em questão. Essas teses explicitam a sua perspectiva epistemológica, ou seja, a teoria orientadora dos estudos, porém não indicam seu posicionamento epistemológico, isto é, seu posicionamento ético-político, que pode ser crítico, crítico-radical, crítico-analítico, dentre outros (TELLO; MAINARDES, 2015a). Há dois casos em que os autores indicam o seu posicionamento epistemológico: perspectiva crítica, humanista e transformadora da educação, à qual são vinculados 28 autores; abordagem teórica crítica e perspectiva crítica, porém nem indica autores referentes, nem tradição teórica, mas os autores vão aparecendo ao longo do texto.

Outra constatação evidenciada é a predominância da indicação de autores. Poucas teses $(25,92 \%)$ indicam a matriz teórica/tradição teórica com seus respectivos autores referentes, sendo o materialismo histórico e dialético de Marx e Engels (3) o mais citado, apontando a continuidade com a pesquisa de Silva e Jacomini $(2014,2016)$. Nessas teses, os pesquisadores deixam claros qual a tradição e quais autores constituem a ancoragem teórica de toda a tese, explicitando a sua perspectiva epistemológica, ou seja, a teoria orientadora dos estudos, porém apenas dois pesquisadores indicaram seu posicionamento epistemológico (TELLO; MAINARDES, 2015a), conforme mostra o Quadro 1.

Quadro 1 - Panorama da apresentação do posicionamento e perspectiva epistemológica nas teses

\begin{tabular}{|c|c|c|c|}
\hline Categorias & $\mathbf{N}^{\mathbf{o}}$ & & Descrição \\
\hline \multirow{2}{*}{$\begin{array}{l}\text { Posicionamento } \\
\text { epistemológico }\end{array}$} & \multirow{2}{*}{2 teses } & $\begin{array}{l}\text { Posicionamento e } \\
\text { autores }\end{array}$ & $\begin{array}{l}\text { Crítica, humanista e transformadora da educação ( } 28 \\
\text { autores referentes). }\end{array}$ \\
\hline & & $\begin{array}{l}\text { Somente o } \\
\text { posicionamento }\end{array}$ & $\begin{array}{l}\text { Crítica, porém não consta a indicação da vertente } \\
\text { teórica e de autores referentes. }\end{array}$ \\
\hline \multirow[t]{2}{*}{$\begin{array}{l}\text { Perspectiva } \\
\text { epistemológica }\end{array}$} & \multirow[t]{2}{*}{21 teses } & $\begin{array}{l}\text { Vertente teórica e } \\
\text { autores referentes } \\
\text { (7) }\end{array}$ & $\begin{array}{l}\text { Materialismo histórico e dialético: Marx e Engels (3); } \\
\text { teoria das representações socias de Moscovici (1); } \\
\text { autores da primeira geração da Escola de Frankfurt: } \\
\text { Adorno, Horkeimer e Marcuse (1); vertente } \\
\text { fenomenológica-hermenêutica: Bruner, Freire e Nóvoa } \\
\text { (1); teoria do pensamento complexo de } \\
\text { Morin/pedagogia da autonomia de Paulo } \\
\text { Freire/reencantar a educação de Hugo Assmann (1). }\end{array}$ \\
\hline & & $\begin{array}{l}\text { Somente autores } \\
(14)\end{array}$ & 2 a 6 autores (6); 11 a 20 autores (4); 28 a 39 autores (4) \\
\hline
\end{tabular}

Fonte: Elaborado pelos autores.

Quanto às teses que apresentaram autores como referencial teórico, foi possível constatar que quanto maior o número de autores, maior a dificuldade de articulação, estando de acordo com o afirmado por Mainardes (2016, 2017, 2018a), por lidarem com um universo amplamente diversificado de concepções e de conceitos, que notadamente impõem grandes dificuldades de articulação. A pulverização de autores e as suas dificuldades de articulação também foram percebidas por Silva e Jacomini (2014, 2016) e Moreira (2019), corroborando a indicação da literatura de que as pesquisas em Política Educacional apresentam fragilidades teóricas. 
Em relação à formulação do problema de pesquisa, identificou-se que a maioria (70,37\%) das teses o fizeram em forma de pergunta. Se considerarmos que o que caracteriza o problema de pesquisa é a sua formulação em forma de pergunta, evidenciaremos que há teses que não o enunciaram de modo explícito. Fato curioso relaciona-se à quantidade de perguntas apresentadas, pois apenas três teses $(11,11 \%)$ apresentaram uma única pergunta. Nas que apresentaram mais de uma pergunta como problema de pesquisa, foi possível identificar que não se tratava do problema propriamente dito, mas de um conjunto de questões a que a tese buscou responder, revelando novamente uma confusão conceitual. Atrelada a tal dificuldade - a falta de clareza de seu problema de pesquisa -, talvez estejam associadas outras dificuldades já sinalizadas, tal como a de apontar quais são as contribuições da pesquisa e a de predominar, na explicitação dos interesses pela pesquisa, a trajetória de vida do pesquisador e não a pertinência do tema para o campo acadêmico.

Em relação às hipóteses de resolução do problema, constatou-se que há um bom número de teses que não a enunciam $(44,44 \%)$ e as demais (55,55\%) apresentam a hipótese inicial, combinada ou não, com o problema de pesquisa. A apresentação da hipótese de modo não combinado com o problema de pesquisa aponta para uma desarmonia que pode ser um indicativo de um problema de compreensão teórica referente à articulação na pesquisa entre o problema e a sua hipótese inicial de resolução, em torno dos quais se definem e organizam os procedimentos metodológicos e a indicação das conclusões da pesquisa.

Diante de tais indicativos, é possível afirmar que é perceptível a continuidade das dificuldades quanto à explicitação nas teses de seu referencial teórico, problema e hipótese de pesquisa, apontando para as fragilidades quanto a perspectiva e o posicionamento epistemológico (TELLO; MAINARDES, 2015a; MOREIRA, 2019). Por tratar-se de autores/pesquisadores que estão desenvolvendo seus trabalhos em nível de Doutorado, constitui-se um grande desafio para os programas de Pós-Graduação a formação desses pesquisadores. Nesse sentido, corrobora-se a afirmação de Silva e Jacomini $(2014,2016)$ de que tais indicativos apontam para a pouca atenção aos dilemas teóricos das pesquisas nesse campo.

A escolha do método e a definição do percurso metodológico são reveladoras do enfoque epistemetodológico (TELLO; MAINARDES, 2015a) das pesquisas, consistindo no modo como se organiza metodologicamente a pesquisa ancorada no referencial teórico. O Quadro 2 aponta para o panorama epistemetodológico das teses analisadas. A escolha do método é reveladora do caminho escolhido pelo pesquisador a fim de construir uma resposta para o seu problema de pesquisa, a qual deve ser lógica e teoricamente válida. Desse modo, trata-se de uma perspectiva de organização lógica dos argumentos apresentados, em outras palavras, da apresentação das premissas que sustentam uma determinada conclusão a partir de um ponto de vista teórico, na construção das quais serão utilizadas técnicas e instrumentos reconhecidos pela comunidade científica como confiáveis, culminando com avaliação dos resultados por meio da crítica intersubjetiva.

Quadro 2 - Panorama epistemetodológico das teses

(continua)

\begin{tabular}{|c|c|l|}
\hline Dimensão metodológica & $\begin{array}{c}\text { Número } \\
\text { de teses }\end{array}$ & \multicolumn{1}{|c|}{ Descrição da dimensão metodológica apresentada nas teses } \\
\hline Método & 7 & $\begin{array}{l}\text { Hermenêutico dialético (1); descritivo-analítico (1); dialético (3); história-oral } \\
\text { (1); estudo de caso (1). }\end{array}$ \\
\hline Natureza da pesquisa & 1 & Básica (1). \\
\hline
\end{tabular}

Fonte: Elaborada pelos autores. 
A pesquisa em Política Educacional: análise de aspectos teórico-epistemológicos...

Quadro 2 - Panorama epistemetodológico das teses

(conclusão)

\begin{tabular}{|c|c|c|}
\hline Dimensão metodológica & $\begin{array}{l}\text { Número } \\
\text { de teses }\end{array}$ & Descrição da dimensão metodológica apresentada nas teses \\
\hline $\begin{array}{c}\text { Pesquisa quanto à } \\
\text { abordagem do problema }\end{array}$ & 21 & Qualitativa (18); qualitativa/quantitativa (3). \\
\hline $\begin{array}{l}\text { Pesquisa quanto aos } \\
\text { objetivos }\end{array}$ & 6 & Exploratória (2); descritiva (1); explicativa (1); descritiva-explicativa (2). \\
\hline $\begin{array}{l}\text { Pesquisa quanto aos } \\
\text { procedimentos técnicos }\end{array}$ & 21 & $\begin{array}{l}\text { Narrativa (auto) biográfica (1); estudo de caso (6); documental (2); } \\
\text { bibliográfica (3); estudo de campo (1); etnográfica/participante (1); estudo de } \\
\text { caso/documental (1); documental/bibliográfica (4); } \\
\text { documental/bibliográfica/levantamento (1); estudo de } \\
\text { caso/bibliográfica/documental (1). }\end{array}$ \\
\hline Lócus da pesquisa & 22 & $\begin{array}{l}\text { Instituições de Educação Superior (9); instituições de educação não formal } \\
\text { (2); Educação Básica (11); não se aplica (5). }\end{array}$ \\
\hline Sujeitos da pesquisa & 21 & $\begin{array}{l}\text { Educação Básica: professores, gestores, funcionários, alunos; Educação } \\
\text { Superior: docentes, alunos, técnico-administrativos e representantes de } \\
\text { órgãos governamentais e associações; educação não formal: profissionais } \\
\text { atuantes; não se aplica (6). }\end{array}$ \\
\hline Coleta de dados & 27 & $\begin{array}{l}\text { Entrevista semiestruturada (3); questionário/análise documental (2); revisão } \\
\text { bibliográfica/análise documental (6); entrevista semiestruturada/grupos } \\
\text { focais (1); observação/grupos focais/entrevistas semiestruturadas (2); } \\
\text { entrevistas semiestruturadas/observações/análise documental/revisão } \\
\text { bibliográfica (6); história oral/resumos de teses e dissertações (1); } \\
\text { questionário/entrevista semiestruturada/análise documental (3); análise } \\
\text { documental/ observação (1); grupos focais/análise de fotos e portfólios (1); } \\
\text { produções de autoria pedagógica/painéis ilustrados/ produções } \\
\text { textuais/portfólios (1). }\end{array}$ \\
\hline $\begin{array}{l}\text { Tratamento e análise dos } \\
\text { dados }\end{array}$ & 22 & $\begin{array}{l}\text { Modelo de análise hermenêutico dialético/quantitativa/estatística } \\
\text { descritiva/Survey (1); discurso do sujeito coletivo/tagueamento/software } \\
\text { qualiquantisoft/teóricos contemporâneos (1); abordagem/método dialética (2); } \\
\text { análise de conteúdo (6); método descritivo-analítico (1); estatísticas } \\
\text { descritiva/análise qualitativa-quantitativa (1); hermenêutica-dialética (1); } \\
\text { análise de conteúdo/análise documental (1); conceitos dos autores da } \\
\text { primeira geração da Escola de Frankfurt (1); teoria/elementos apreendidos } \\
\text { empiricamente/Software Statiscal Package for Social Sciences (1); Statistical Package } \\
\text { for the Social Sciences/procedimentos quantitativos-qualitativos/análise de } \\
\text { conteúdo (1); Programa SPSS for Windows (1); discurso do sujeito seletivo } \\
\text { (1); análise descritiva simples (1); análise de conteúdo/documental primária } \\
\text { (1). }\end{array}$ \\
\hline
\end{tabular}

Fonte: Elaborado pelos autores.

No conjunto de teses analisadas, percebeu-se que a grande maioria dos autores não identifica o método que orientou e conduziu a atividade de pesquisa. Desse modo, é possível inferir que a maioria dos pesquisadores $(74,07 \%)$ desconsidera tal dimensão da produção do conhecimento científico. Isso não quer dizer que as teses não organizem logicamente seus argumentos, mas que estes foram levados adiante sem muita clareza a respeito do método orientador, partindo da concepção de que o esclarecimento da natureza da pesquisa e a descrição dos procedimentos são suficientes para demonstrar a validade das conclusões. Isso aponta para outra fragilidade das pesquisas.

Práxis Educativa, Ponta Grossa, v. 15, e2014901, p. 1-21, 2020 Disponível em: <https://www.revistas2.uepg.br/index.php/praxiseducativa> 
A predominância de pesquisas qualitativas está de acordo com o apontado pelas pesquisas de Martins (2011) e Diógenes (2014); a não ocorrência de pesquisa quantitativas segue a tendência apontada por Martins (2011) de busca pela compreensão da complexidade dos processos interativos entre os atores sociais, para o qual as pesquisas quantitativas são limitadas; as qualitativas e quantitativas, apesar de pouca representatividade, são destacadas por Martins (2011) e Diógenes (2014) como possibilidades de melhor analisar as representações sociais e as diversas posições que formam o universo da pesquisa.

Quanto aos objetivos, apenas seis teses apresentam a caracterização da pesquisa. Nesse contexto, os estudos exploratórios e os estudos combinados (descritivos-explicativos) contaram com duas teses cada; e a descritiva e explicativa, com uma indicação cada. No entanto, o que chamou atenção foi que a grande maioria das teses não apresenta tal informação, seja por desconhecimento ou por considerar irrelevante.

$\mathrm{Na}$ caracterização das teses quanto aos procedimentos técnicos, constatou-se uma maior diversidade, em que estudos de casos ganham destaque, seguidos das pesquisas bibliográficas e documentais. Chamam atenção as pesquisas de abordagem híbrida, ou seja, que se caracterizam por utilizar mais de uma abordagem de forma combinada (7). No entanto, as que apontaram na combinação a pesquisa bibliográfica, parecem fazer confusão entre revisão de literatura e pesquisa bibliográfica, o que será evidenciado mais adiante quando se tratar do lócus, sujeitos e coleta de dados das pesquisas.

O lócus privilegiado das pesquisas analisadas foi a Educação Básica brasileira, com 11 teses voltadas à análise da Educação Infantil, Ensino Fundamental e Ensino Médio, sendo quase a sua totalidade voltada às escolas públicas, com exceção de um estudo voltado à Educação Infantil que considerou escolas públicas e privadas. Destaca-se que são estudos voltados à compreensão de realidades brasileiras bem específicas tomadas em seu contexto, sem comparação a estudos semelhantes ou mais amplos, conforme apontado por Krawczyk (2012) e consideraram a concretude da política e seus impactos no cotidiano escolar (MARTINS, 2011). Desse modo, é possível afirmar que as teses analisadas seguem a tendência apontada por Bello, Jacomini e Minhoto $(2014,2016)$ de que a grande maioria dos estudos de teses e de dissertações, no período de 2008 2010, estudaram a realidade brasileira (1.231), e poucos se dedicaram a estudos comparativos internacionais (29).

As pesquisas que tiveram como lócus as instituições de Educação Superior brasileiras foram nove, sendo os cursos de formação de professores os mais estudados. Tal perfil reiterou a tendência de serem estudos bem localizados e sem preocupação com comparações com estudos maiores ou mesmo de pesquisa comparada. Duas pesquisas direcionaram seu foco para instituições de educação não formal, uma delas ligada à formação profissional de uma indústria do setor automotivo e a outra para instituições de acolhimento de crianças e de adolescentes em estado de vulnerabilidade social. As cinco pesquisas em que o percurso metodológico não exigia a definição de um lócus de pesquisa eram bibliográfica e/ou documental.

Em relação aos sujeitos da pesquisa, é possível observar que, na Educação Básica, a grande maioria é composta por docentes da Educação Infantil e do Ensino Fundamental, seguidos dos gestores (diretores e coordenadores) e de alunos. Na Educação Superior, os docentes também são a maioria, visto que as funções de coordenação são exercidas por eles, seguidos dos alunos/as, técnico-administrativos e representantes de órgãos governamentais e associações como a Associação Brasileira de Ensino Odontológico (Abeno). No caso da educação não formal, os sujeitos são todas os profissionais que atuam nas casas de acolhimento. A tendência das pesquisas de Política Educacional em ter como foco as ações de seus implementadores foi apontada por Martins ( (2011). 
A pesquisa em Política Educacional: análise de aspectos teórico-epistemológicos...

Quanto aos instrumentos utilizados para a coleta de dados, observa-se que a grande maioria das teses utiliza mais de um instrumento. Apenas sete teses afirmam utilizar apenas um instrumento: entrevistas semiestruturadas, questionário, análise documental e revisão bibliográfica. As demais utilizam instrumentos combinados, de modo a garantir a triangulação. Destaca-se, nesse sentido, o uso de entrevista semiestruturada, que aparece em 14 teses, caracterizando-se, assim, como o instrumento mais utilizado.

Quanto ao tratamento e à análise dos dados, percebeu-se uma grande variedade de combinações. Destaca-se, no entanto, a diferença entre o tratamento dos dados em que se pode recorrer a diferentes softwares ou não, de modo a organizar o material recolhido de forma coerente e de acordo com os objetivos da pesquisa e a análise dos dados. A análise seria um passo posterior, no qual, após os dados organizados de modo coerente, se analisam as suas implicações para a resolução do problema de pesquisa e se a sua hipótese se confirma ou não. Esse segundo momento, a análise, é o momento de construir a interpretação a respeito dos achados da pesquisa à luz da teoria. O que chama atenção foi que apenas três teses fazem menção ao referencial teórico no momento de análise, sendo duas delas de modo vago (teóricos contemporâneos, relações e conexões entre a teoria e os elementos apreendidos empiricamente) e outra de modo mais específico (conceitos preconizados pelos autores da primeira geração da Escola de Frankfurt).

No caso da primeira, percebe-se a imprecisão teórica apresentada nos elementos textuais da tese, pois a afirmação de que o referencial teórico da tese tem relação com "teóricos contemporâneos sobre a docência e as políticas educacionais" nada esclarece a respeito das concepções que sustentariam suas análises. No caso da segunda (relações e conexões entre a teoria e os elementos apreendidos empiricamente), percebe-se uma imprecisão conceitual, pois, nos elementos textuais, é indicado um amplo conjunto de autores como referencial teórico, e, na análise dos dados, fala de teoria no singular, quando o que acontece no seu texto é apresentação de uma combinação dos autores citados e não de uma teoria específica. Nesse caso, a imprecisão conceitual gera certa confusão, pois não se trata da teoria, mas de conceitos obtidos a partir de um referencial teórico composto de um amplo conjunto de autores. A terceira tese (conceitos preconizados pelos autores da primeira geração da Escola de Frankfurt) aponta mais coerência e consistência quanto ao seu referencial teórico, o qual é anunciado no resumo e nos elementos textuais juntamente aos conceitos que orientarão as análises.

\section{Conclusões}

A identificação das dimensões propostas pelo EEPE - posicionamento, perspectiva e enfoque epistemetodológico - permite afirmar que a explicitação da dimensão teórica das pesquisas coloca maiores dificuldades para os pesquisadores do que a dimensão metodológica. É interessante notar que Bachelard e Popper afirmam com veemência tal tendência, qual seja, da ênfase dada aos procedimentos das pesquisas em detrimento dos teóricos, já que, para eles, é justamente o contrário que deveria acontecer, sendo a escolha qualificada dos procedimentos metodológicos uma decorrência da clareza e da consistência teórica. Nessa direção, aponta-se que as pesquisas de Política Educacional ainda apresentam fragilidades epistemológicas, principalmente ligadas à sua dimensão teórica, o que acarreta a dificuldade de superar os obstáculos epistemológicos-ideológicos e de colocar em ação a vigilância epistemológica. Tal fragilidade é um dos desafios impostos aos processos formativos dos pesquisadores em nível de Mestrado ou Doutorado, os quais necessitam de maiores investimentos nas discussões a respeito das questões epistemológicas da pesquisa em Política Educacional.

A análise dos núcleos temáticos das linhas de pesquisa mostrou que nenhuma delas sinaliza de modo explícito a intencionalidade de investigação a respeito da produção do conhecimento no

Práxis Educativa, Ponta Grossa, v. 15, e2014901, p. 1-21, 2020

Disponível em: <https://www.revistas2.uepg.br/index.php/praxiseducativa> 
campo acadêmico da Política Educacional. A consolidação do campo e a superação de suas fragilidades epistemológicas passa pelo interesse científico de tematizar, de pesquisar e de discutir a respeito das questões epistemológicas das pesquisas em Política Educacional, uma vez que é a partir desse movimento e dessa intencionalidade que se poderá qualificar as pesquisas do campo. Desse modo, a intencionalidade das linhas em fomentar tais abordagens é um elemento importante para o desenvolvimento de estudos voltados a tais temáticas.

A cientificidade é garantida pelo esforço teórico de compreensão, o qual permite a seleção do método e dos instrumentos para a produção de determinados resultados a partir da compreensão teórica. Por isso, quando se trata de compreender epistemologicamente as explicações científicas, é necessário considerar as dimensões teóricas e metodológicas imbrincadas na produção do conhecimento, sendo uma decorrência de tal relação um indicativo de qualidade e confiabilidade das pesquisas. Nessa direção, pode-se afirmar que as teses de Política Educacional defendidas no triênio 2010-2012, como já mostrado pela literatura, apresentam fragilidades epistemológicas devido à dificuldade em articular os elementos teóricos e metodológicos, evidenciada pela não enunciação clara desses elementos no texto das teses, assim como pelas dificuldades de explicitar quais são as contribuições da pesquisa para o campo acadêmico a que estão vinculadas. O aprimoramento de tais dimensões consiste em um desafio para os Programas de Pós-Graduação, já que são responsáveis pela qualificação da produção acadêmica por meio da formação de pesquisadores, da proposição e do fomento de discussões voltadas à produção do conhecimento no campo, da crítica e da denúncia das condições de produção do conhecimento na academia e das disputas de poder no cenário de produtivismo acadêmico e de constituição das elites acadêmicas.

\section{Referências}

BACHELARD, G. O novo espírito científico. Rio de Janeiro: Tempo Brasileiro, 1968.

BACHELARD, G. O racionalismo aplicado. Rio de Janeiro: Zahar Editores, 1977.

BACHELARD, G. A filosofia do não: filosofia do novo espírito científico. São Paulo: Abril Cultural, 1979.

BACHELARD, G. O materialismo racional. Rio de Janeiro: Edições 70, 1990.

BACHELARD, G. A formação do espírito científico: contribuições para uma psicanálise do conhecimento. Rio de Janeiro: Contraponto, 1996.

BARDIN, L. Análise de conteúdo. São Paulo: Edições 70, 2011.

BELlo, I. M.; JACOMINI, M. A.; MINHOTO, M. A. P. Pesquisa em Política Educacional no Brasil (2000-2010): uma análise de teses e dissertações. Práxis Educativa, Ponta Grossa, v. 9, n. 2, p. 369-393, jul./dez. 2014. DOI: https://doi.org/10.5212/PraxEduc.v.9i2.0004

Bello, I. M.; JACOMINI, M. A.; MINHOTO, M. A. P. Produção Acadêmica em Política Educacional no Brasil: análise de teses e dissertações (2000-1010). In: SILVA, A. A.; JACOMINI, 
M. A.; (orgs.). Pesquisa em políticas educacionais: características e tendências. Feira de Santana: UEFS Editora, 2016. p. 63-92.

BHASKAR, R. Reclaiming reality: a critical introduction to contemporary Philosophy. London: Verso, 1993.

CAPES. Cadernos de Indicadores. Brasília: Ministério da Educação, 2010. Disponível em: $<$ http://conteudoweb.capes.gov.br/conteudoweb/CadernoAvaliacaoServlet>. Acesso em: 27 jul. 2016.

CAPES. Cadernos de Indicadores. Brasília: Ministério da Educação, 2011. Disponível em: $<$ http://conteudoweb.capes.gov.br/conteudoweb/CadernoAvaliacaoServlet>. Acesso em: 27 jul. 2016.

CAPES. Cadernos de Indicadores. Brasília: Ministério da Educação, 2012. Disponível em: $<$ http://conteudoweb.capes.gov.br/conteudoweb/CadernoAvaliacaoServlet>. Acesso em: 27 jul. 2016.

DIÓGENES, E. M. N. Análise das bases epistemológicas do campo teórico da Política Educacional. Práxis Educativa, Ponta Grossa, v. 9, n. 2, p. 333-353, jul./dez. 2014. DOI: https://doi.org/10.5212/PraxEduc.v.9i2.0002

ESPINOZA, O. Reflexiones sobre los conceptos de "política", políticas públicas y política educacional. Education Policy Analysis Archives, [online], v. 17, n. 8, p. 1-13, abr. 2009.

ESTEBAN, M. P. S. Pesquisa qualitativa em educação: fundamentos e tradições. Porto Alegre: AMGH, 2010.

FÁVERO, A. A.; TONIETO, C. The place of the theory in educational policy research. Revista de Estudios Teórico e Epistemológicos en Política Educativa, v. 1, n. 2, p. 1-19, jul./dez. 2016.

FREY, K. Políticas públicas: um debate conceitual e reflexões referentes à prática da análise de políticas públicas no Brasil. Planejamento e políticas públicas, Brasilia, v. 1, n. 21, p. 211-258, jun. 2000.

GATTI, B. A. A construção metodológica da pesquisa em educação: desafios. Revista Brasileira de Política e Administração da Educação, Goiânia, v. 28, n. 1, p. 13-34, jan./abr. 2012. DOI: https://doi.org/10.21573/vol28n12012.36066

GUimarÃES, I. P. Um estudo das elites acadêmicas no campo da Política Educacional no Brasil. Práxis Educativa, Ponta Grossa, v. 14, n. 1, p. 273-296, jan./abr. 2019. DOI: https://doi.org/10.5212/PraxEduc.v.14n1.015 
KRAWCZYK, N. A historicidade da pesquisa em Política Educacional: o caso do Brasil. Jornal de Política Educacionais, Curitiba, v. 6, n. 12, p. 03-11, jul./dez. 2012. DOI: http://dx.doi.org/10.5380/ipe.v6i12.32270

MACEDO, E.; SOUZA, C. P. D. A pesquisa em educação no Brasil. Revista Brasileira de Educação, Rio de Janeiro, v. 15, n. 43, p. 166-167, jan./abr. 2010. DOI: https://doi.org/10.1590/S1413-24782010000100012

MAINARDES, J. Análise de política educacionais: breves considerações teórico-metodológicas. Contrapontos, Itajaí, v. 9, n. 1, p. 4-16, jan./abr. 2009.

MAINARDES, J. A pesquisa sobre Política Educacional no Brasil: aspectos teóricoepistemológicos. 2016. In: REUNIÃO CIENTÍFICA REGIONAL DA ANPED - ANPED SUL, 11., 2016, Curitiba-PR. Anais eletrônicos [...]. Curitiba-PR: Setor de Educação da UFPR, 2016. p. 1-7. Disponível em: <http://www.anpedsul2016.ufpr.br/portal/wpcontent/uploads/2015/11/Jefferson-Texto-Anped-sul-2016.pdf>. Acesso: 12 dez. 2016

MAINARDES, J. A pesquisa sobre Política Educacional no Brasil: análise de aspectos teórico epistemológicos. Educação em Revista, Belo Horizonte, v. 33, p. 1-25, 2017. DOI: https://doi.org/10.1590/0102-4698173480

MAINARDES, J. A pesquisa no campo da Política Educacional: perspectivas teóricoepistemológicas e o lugar do pluralismo. Revista Brasileira de Educação, Rio de Janeiro, v. 23, p. 1-20, 2018a. DOI: $\underline{\text { https://doi.org/10.1590/s1413-24782018230034 }}$

MAINARDES, J. Metapesquisa no campo da Política Educacional: elementos conceituais e metodológicos. Educar em Revista, Curitiba, v. 34, n. 72, p. 303-319, nov./dez. 2018b. DOI: https://doi.org/10.1590/0104-4060.59762

MAINARDES, J.; TELLO, C. Research on the field of education policy: exploring different levels of approach and abstraction. Education Policy Analysis Archives, v. 24, n. 75, p. 1-16, 2016. DOI: https://doi.org/10.14507/epaa.24.2331

MAINARDES, J.; STREMEL, S. (Eds.). Education policy research: epistemological and theoretical issues. Curitiba: Brazil Publishing, 2020.

MARTINS, A. M. A pesquisa na área de política e gestão da Educação Básica: aspectos teóricos e metodológicos. Educação \& Realidade, Porto Alegre, v. 36, n. 2, p. 370-393, maio/ago. 2011.

MORAES, M. C. M. Recuo da Teoria. In: MORAES, M. C. M. (org.). Iluminismo às avessas: produção de conhecimento e políticas educacionais. Rio de Janeiro: DP\&A, 2003. p. 151-167.

MORAES, M. C. M. Indagações sobre o conhecimento no campo da educação. In: ALMEIDA, M. L. P.; MENDES, V. H. (Orgs.). Educação e racionalidade: questões de ontologia e método em educação. Campinas: Mercado de Letras, 2009. p. 21-53. 
MOREIRA, L. P. O Programa Universidade Para Todos em teses da área de Educação: temáticas, fundamentos e níveis de abstração. Práxis Educativa, Ponta Grossa, v. 14, n. 3, p. 1-21, set./dez. 2019. DOI: https://doi.org/10.5212/PraxEduc.v.14n3.004

OLIVEIRA, J. F. D. A Pós-Graduação e a pesquisa no Brasil: processos de regulação e de reconfiguração da formação e da produção do trabalho acadêmico. Práxis Educativa, Ponta $\begin{array}{llllllll}\text { Grossa, } & \text { v. } & 10, & \text { n. } & 2, & \text { p. } & 343-363, & \text { jul./dez. }\end{array}$ DOI: https://doi.org/10.5212/PraxEduc.v.10i2.0004

POPPER, K. R. Conhecimento objetivo: uma abordagem evolucionária. São Paulo: Editora da Universidade de São Paulo, 1975.

POPPER, K. R. A lógica das ciências sociais. 3. ed. Rio de Janeiro: Tempo Brasileiro, 2004.

POPPER, K. R. Conjecturas e refutações: o progresso do conhecimento científico. 5. ed. Brasília: Editora da Universidade de Brasília, 2008.

POPPER, K. R. A lógica da pesquisa científica. 2. ed. São Paulo: Cultrix, 2013.

SILVA, A. A.; JACOMINI, M. A. A pós-graduação e a produção acadêmica em políticas educacionais: questões epistemológicas. In: JORNADAS LATINOAMERICANAS DE ESTUDIOS EPISTEMOLÓGICOS EN POLÍTICA EDUCATIVA, 2., 2014, Curitiba-PR. Anais eletrônicos [...]. Curitiba-PR: UFPR, 2014. p. 1-26. Disponível em: <http://www.relepe.org/images/675.pdf>. Acesso em: 10 set. 2016.

SILVA, A. A.; JACOMINI, M. A. Escolhas políticas e (re) direcionamentos epistemológicos em educação: um panorama de teses e dissertações. In: SILVA, A. A.; JACOMINI, M. A. (orgs.). Pesquisa em políticas educacionais: características e tendências. Feira de Santana: UEFS Editora, 2016. p. 93-122.

SOUZA, A. R. D. A pesquisa em políticas educacionais no Brasil: de que estamos tratando? Práxis Educativa, Ponta Grossa, v. 9, n. 2, p. 355-367, jul./dez. 2014. DOI: https://doi.org/10.5212/PraxEduc.v.9i2.0003

TELLO, C. Las epistemologias de la política educativa: vigilancia y posicionamiento epistemológico del investigador en política educativa. Práxis Educativa, Ponta Grossa, v. 7, n. 1, p. 53-66, jan./jun. 2012. DOI: https://doi.org/10.5212/PraxEduc.v.711.0003

TELLO, C. La produción de conocimiento en Política Educacional: entre los nuevos modos de producción de conocimiento y el EEPE. Diálogo Educacional, Curitiba, v. 13, n. 39, p. 749-770, maio/ago. 2013. DOI: http://dx.doi.org/10.7213/dialogo.educ.10212

TELLO, C.; MAINARDES, J. La posición epistemológica de los investigadores en Política Educativa: debates teóricos en torno a las perspectivas neo-marxista, pluralista y pos-estruturalista. Education Policy Analysis Archives [online], v. 20, n. 9, p. 1-36, mar. 2012. DOI: http://doi.org/10.14507/epaa.v20n9.2012 
TELLO, C.; MAINARDES, J. Revisitando o enfoque das epistemologias da Política Educacional. Práxis Educativa, Ponta Grossa, v. 10, n. 1, p. 153-178, jan./jun. 2015a. DOI: https://doi.org/10.5212/PraxEduc.v.10i1.0007

TELLO, C.; MAINARDES. Pluralismos e investigación en política educativa una perspectiva epistemológica. Revista Mexicana de Investigación Educativa, México, v. 20, n. 66, jul./sep. 2015b.

TONIETO, C. Características epistemológicas das teses de Política Educacional no triênio 2010-2012. 214 f. Tese (Doutorado em Educação) - Universidade de Passo Fundo, Passo Fundo, 2018.

Recebido em 31/12/2019

Versão corrigida recebida em 27/02/2020

Aceito em 28/02/2020

Publicado online em 10/03/2020 